\title{
LEFT VENTRICULAR PRESSURES IN PATIENTS WITH AORTIC INSUFFICIENCY STUDIED BY INTRACARDIAC CATHETERIZATION
}

\author{
BY HENRY A. ZIMMERMAN \\ (From the Department of Medicine, Western Reserve University, City Hospital Division, \\ Cleveland, Ohio)
}

(Submitted for publication June 22, 1950; accepted, September 21, 1950)

The purpose of this communication is to report on the pressure levels recorded within the cavity of the left ventricle in ten human subjects with aortic insufficiency. The technique of catheterization has been described in detail $(1)$; it should be again emphasized that this may be a hazardous procedure. However, the Mexico workers have carried out 56 left ventricle catheterizations without incident. Pressure tracings were inscribed by means of the Brush Six Channel Oscillograph (2).
The recording reference point was the antecubital fossa of the outstretched and level arm, approximately $5 \mathrm{~cm}$. below the level of the sternum. Figure 1 shows simultaneous pressure tracings from the left and right ventricles and femoral artery.

Obvious congestive failure was present in seven patients, and absent in three at the time of study. Numerous investigators (3-6) have shown by catheterization of the right side of the heart, that

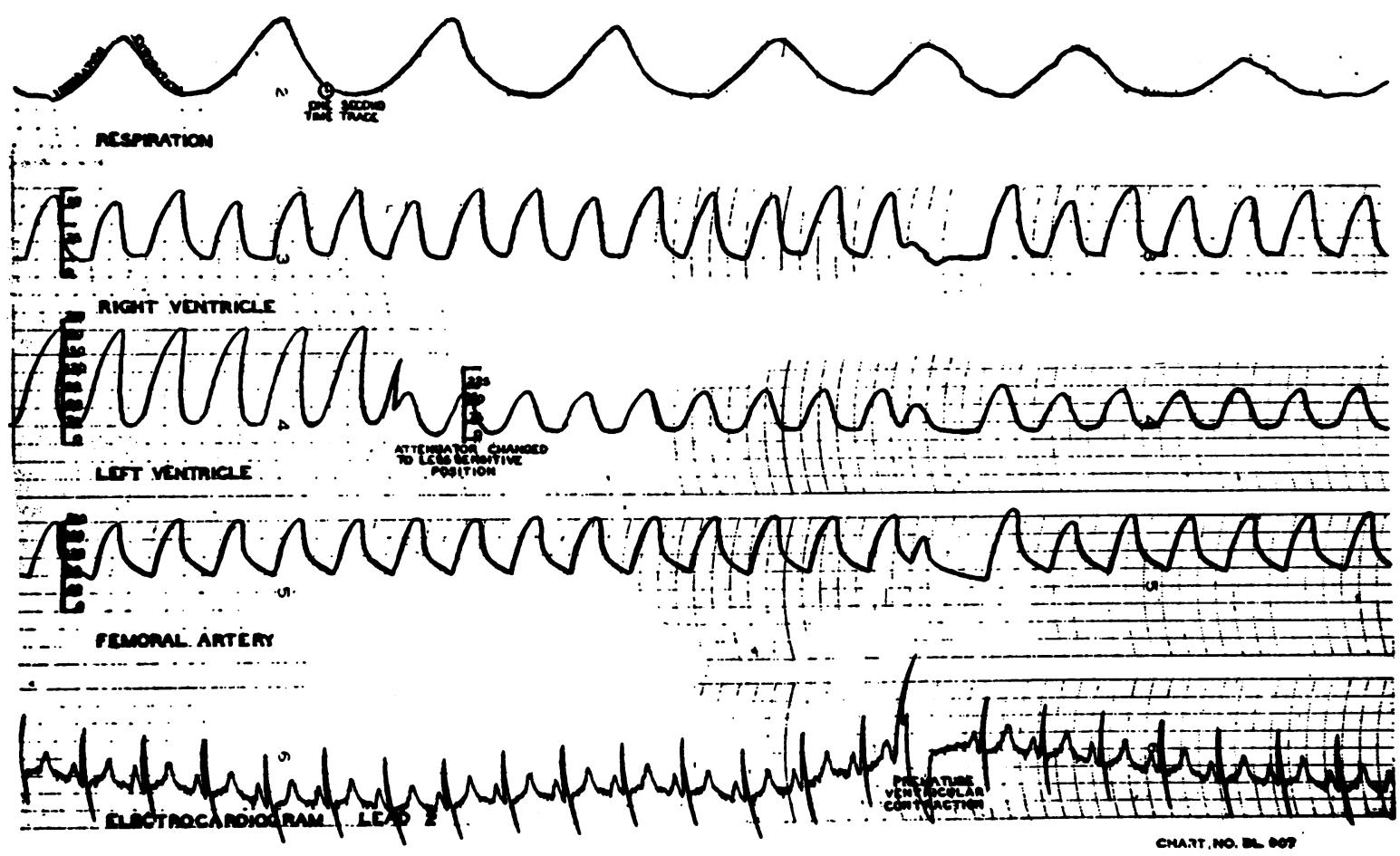

Fig. 1. A Representative Tracing Recorded by the Brush Six Channel Oscillograph Showing Phase of Respiration, Right Ventricular Pressure, left Ventricular Pressure, Femoral Arterial Pressure AND LEAd 2 OF THE Electrocardiogram

The chart speed was $25 \mathrm{~mm}$./sec. Note the mechanical alterans present in the pressure tracings. 
TABLE I

Pressure levels within left ventricle, aorta (above valoe), right ventricle and right auricle in ten patients with aortic insufficiency.* All values are expressed in $\mathrm{mm}$. of mercury.

\begin{tabular}{|c|c|c|c|c|}
\hline $\begin{array}{l}\text { Patient, } \\
\text { sex, age }\end{array}$ & $\begin{array}{c}\text { Lt. } \\
\text { ventricle }\end{array}$ & $\begin{array}{l}\text { Aorta } \\
\text { (above } \\
\text { valve) }\end{array}$ & $\begin{array}{c}\text { Rt. } \\
\text { ventricle }\end{array}$ & Rt. auricle \\
\hline
\end{tabular}

Patients in Congestive Failure

\begin{tabular}{l|l|l|l|l|l|l|l|}
\hline C. R., M., 43 & $178 / 26$ & $179 / 87$ & $33 / 11.2$ & $13 / 6.2$ \\
\hline
\end{tabular}

W. C., M., $48 \quad 150 / 18$ 146/51 $38 / 7$ 9/1.5 (M.P. 7.1)

C. J., M., 50 112/30 $114 / 63 \quad 64 / 14 \quad 15 / 7 \ddagger$ (M.P. 12.2) J. S., M., 65 190/15 $191 / 75 \quad 46 / 11.2$ 11/8

E. T., F., $46 \quad 147 / 39143 / 87$

A. C., M., 62

L. J., M., 56

$117 / 27 \mid 136 / 67$

$135 / 27132 / 87$

Patient not in Congestive Failure

\begin{tabular}{l|r|r|c|cc}
\hline P. R., M., 42† & $190 / 0$ & $193 / 70$ & $56 /-.5$ & $9 / 28$ & \\
J. D., M., 54 & $88.5 / 0$ & $90 / 48$ & - & & - \\
R. R., M., 49 & $117 / 4$ & $114 / 80$ & - & & - \\
\hline
\end{tabular}

* In those cases in which right ventricular pressure is recorded, both right and left ventricular pressures were inscribed simultaneously. Aortic pressures were recorded just before introduction of the catheter into the left ventricle and again immediately after withdrawal.

t This patient had a low grade coarctation of the aorta with an insufficient bicuspid aortic valve. All other patients had syphilitic aortic insufficiency.

$\ddagger$ Right auricular pressures were not recorded simultaneously with right ventricular pressures.

8 The right auricular pressure is elevated but the right ventricular diastolic pressure, which is the best objective evidence for cardiac failure, is normal.

the right ventricular diastolic pressure is elevated beyond the normal range of 0 to $5 \mathrm{~mm}$. of mercury in congestive failure. Our data indicate that in left ventricular failure, the left ventricular diastolic pressure is likewise elevated (Table I).

In the three patients without evidence of failure, diastolic pressure levels of 0,0 , and $4 \mathrm{~mm}$. of mercury were recorded, an average of $1.3 \mathrm{~mm}$. of mercury; in the seven patients with congestive failure the left ventricular diastolic pressure ranged between 15 and $39 \mathrm{~mm}$.; with an average pressure of $25 \mathrm{~mm}$. of mercury.

These observations support the conclusions of Wiggers (7). From his studies of the hemodynamic changes created by inducing acutely aortic insufficiency in dogs, he concluded that the amount of blood regurgitated into the left ventricle in human aortic insufficiency may be quite small. When aortic incompetency is thus artificially induced, left ventricular diastolic pressure rises immediately. The low diastolic pressure levels obtained in the three subjects without failure may reasonably be explained by the assumption that during the slow development of rheumatic or syphilitic aortic insufficiency, the left ventricle can compensate for the relatively small and slowly incremental reflux of blood by an alteration in its distensibility. In this fashion diastolic filling pressure would be maintained within normal limits compatible with levels most efficient for cardiac function.

The consistent rise in left ventricular diastolic pressure noted in the seven patients in congestive failure is in keeping with Starling's concept of the failure mechanism: a progressive accumulation of blood within the left ventricular cavity, accompanied by a progressive stretching of the myocardium until a critical point is reached where the muscle fibers offer an increasing resistance to the incoming blood, with a resultant rise in the intracavity diastolic pressure. The elevated diastolic pressure levels we have recorded are likewise in agreement with the demonstration by Nylin and Celander (8), that the human ventricles in congestive failure do not empty completely, permitting a large amount of residual blood to remain within the ventricular cavity following systole.

There are certain limitations in securing accurate pressure curves through the $100 \mathrm{~cm}$. plastic catheter in use at the present time. This makes mandatory a repetition of this work with the use of more precise recording equipment, such as the catheter tip strain gauge, now under development in several laboratories.

\section{SUMMARY}

1. The pressure levels within the left ventricular cavity have been studied in ten human subjects with aortic insufficiency by catheterization of the left ventricle via the radial artery.

2. The three patients who exhibited no clinical evidence of congestive failure had normal left ventricular diastolic pressures.

3. The seven patients in obvious congestive failure demonstrated significant increases in diastolic pressure, averaging $25 \mathrm{~mm}$. or mercury.

\section{ACKNOWLEDGMENTS}

The author is indebted to Miss Gladys Heckman, R.N., and Miss Hanna Janouskevec, R.N., for their technical assistance. 


\section{BIBLIOGRAPHY}

1. Zimmerman, H. A., Scott, R. W., and Becker, N. O., Catheterization of the left side of the heart in man. Circulation, 1950, 1, 357.

2. Zimmerman, H. A., and Scott, R. W., Direct writing six channel oscillograph. J. Lab. \& Clin. Med., 1950, 36, 140.

3. Bloomfield, R. A., Lawson, H. D., Cournand, A., Breed, E. S., and Richards, D. W., Jr., Recording of right heart pressures in normal subjects and in patients with chronic pulmonary disease and various types of cardio-circulatory disease. J. Clin. Invest., 1946, 25, 639.

4. Bloomfield, R. A., Rapoport, B., Milnor, J. P., Long, W. K., Mebane, J. C., and Ellis, L. B., The effects of the cardiac glycosides upon the dynamics of the circulation in congestive heart failure. I. Ouabain. J. Clin. Invest., 1948, 27, 588.

5. Richards, D. W., Jr., Contributions of right heart catheterization to the physiological study of congestive heart failure. Am. J. Med., 1947, 3, 434.

6. Stead, E. A., Jr., Warren, J. V., and Brannon, E. S., Effects of lanatoside $C$ on the circulation of patients with congestive failure. Arch. Int. Med., 1948, 81, 282.

7. Wiggers, C. J., Magnitude of regurgitation with aortic leaks of different sizes; review of experimental work. J. A. M. A., 1931, 97, 1359.

8. Nylin, C., and Celander, H., Determination of blood volume in the heart and lungs and the cardiac output through the injection of radiophosphorous. Circulation, 1950, 1, 76. 